\section{Monolayers of the Globulin, Arachin}

VARIOUs methods for spreading proteins have been devised. The method used by Gorter and Grendel ${ }^{1}$ is to drop a fairly concentrated aqueous protein solution very carefully from the least possible height on to the clean water surface in the trough. Hughes et al. ${ }^{2}$ found that solid particles of protein spread very rapidly on a clean substrate surface. These methods proved to be unsuccessful for the spreading of arachin. Arachin was also not soluble in the aqueous propyl alcohol sodium acetate mixture recommended by Ställberg and Teorell ${ }^{3}$. Very satisfactory monolayers of egg albumin and $\beta$-lactoglobulin were obtained by Bull ${ }^{4}$ by using 35 per cent ammonium sulphate as the underlying solution. Accordingly, arachin was next spread on strong ammonium sulphate solutions, and films stable up to high film pressures were obtained. The ammonium sulphate was of analytical quality and the solutions were treated with activated carbon black to remove all surface-active impurities.

The fore - area curve obtained when $0 \cdot 10$ c.c. of a 0.0271 per cent arachin solution in borate buffer, $I=0 \cdot 1$ and $p \mathrm{H}=8 \cdot 9$, was spread on a 40 per cent ammonium sulphate solution, is shown in Fig. 1. The time elapsing between spreading and the start of compression was $10 \mathrm{~min}$. A typical protein film was obtained. It is of interest to note that no collapse of the film was observed at a force as high as 27 dynes $/ \mathrm{cm}$. This force corresponds to a film area of 0.43 sq. m. per mgm., a value which was obtained consistently. Bull ${ }^{5}$ reported an average value of $0.78 \mathrm{sq} . \mathrm{m}$. per mgm. as the smallest area to which most of the reported films can be subjected and remain uncollapsed. It would therefore appear that arachin films may be compressed to very small areas and remain uncollapsed.

The graph of force $\times$ area $(F A)$ against force $(F)$ for arachin films is shown in Fig. 2, and the resulting equation is :

$$
F A=0.818 F+0.100 \text {. }
$$

The extrapolated value of $F A$ at zero film pressure is, accordingly, $0 \cdot 100$ orgs and the film molecular weight $24 \cdot 6 \times 10^{2} / 0 \cdot 100=24,600$. The bulk mole. cular weight of the parent arachin molecule is $340,000^{6}$. In an earlier paper ${ }^{7}$ dissociation of arachin into two sub-units was observed. It would therefore

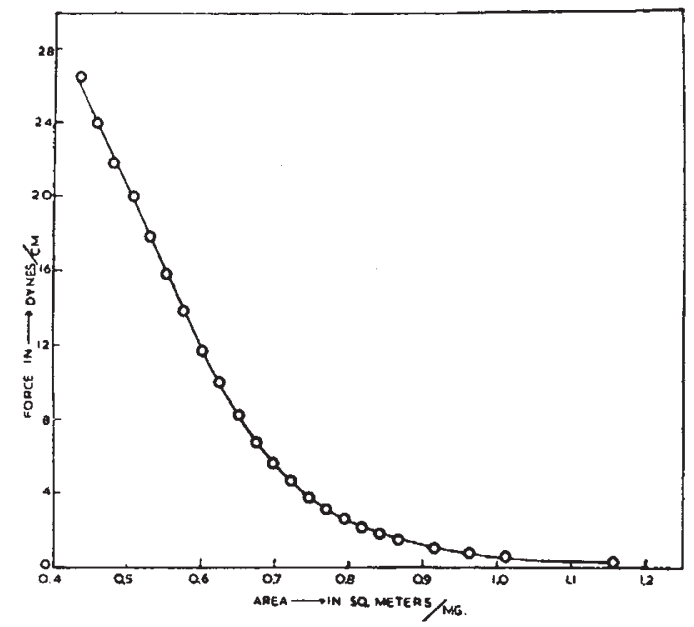
Fig. 1. Force-area curve for arachin films on 40 per cent ammonium
sulphate

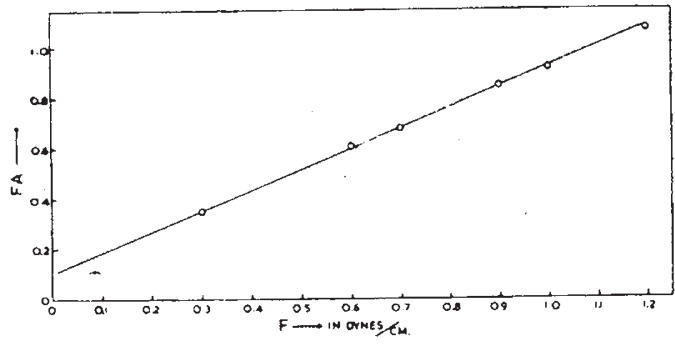

Fig. 2. Film-pressure multiplied by the corresponding film-area plotted against the film pressure

appear that, when arachin is spread on a surface, unfolding of the globular molecule is followed by dissociation into relative small fragments. Several reports have been recorded of dissociation of proteins when spread on a surface ${ }^{5}$.

A similar breakdown has been observed when arachin was treated with the sodium salt of longchain paraffin sulphates ${ }^{8}$. Calculations from sedimentation and diffusion data have shown that complexes with the detergents have been formed, in which the weight of protein per molecule of complex is about 27,000 . This is approximately the same as the surface molecular weight, and suggests that both surface spreading and complex formation have dissociated the arachin molecule in a similar manner.

This communication is published with the permission of the South African Council for Scientific and Industrial Research. I am greatly indebted to Sir Eric Rideal, in whose laboratory the work was undertaken, for his interest and criticism at all times.

National Chemical Research Laboratory, F. J. JoUBERT

Pretoria.

Aug. 25 .

${ }^{1}$ Gorter, E., and Grendel, F., Proc. K. Akad. Amsterdam, 29, 371 (1925). ${ }^{2}$ Hughes, A. H., Schulman, J. H., and Rideal, E. K., Nature, 129, 21 (1932).

${ }^{3}$ Ställberg, S., and Teorell, T., Trans. Farad. Soc., 35, 1413 (1939).

" Bull, H. B., J. Amer. Chem. Soc., 67, 10 (1945).

5 Bull, H. B., "Advances in Protein Chem.", 3, 95 (1947).

'Johnson, P., and Shooter, E. M., Biochim. et Biophys. Acta, 5, 361 (1950).

'Johnson, P., Trans. Farad. Soc., 42, 36 (1946).

s Johnson, P., and Joubert, F. J., J. Polymer Sci., 7, 605 (1951).

\section{A Method of Preparing Crystals that Undergo Changes under Electron Bombardment in an Electron Microscope}

OBSERVATIONS of pseudo-structures in the electron microscope have been reported by several authors. This phenomenon has been fully reported by Burton et al. ${ }^{1}$ and by Watson and Preuss" for sodium chloride crystals. We have devised a reproducible method for the preparation of sodium chloride crystals which undergo such changes in an $R C A$ electron microscope, model $E M U$, fitted with an unbiased gun. It was observed that crystals obtained by drying aqueous solutions of sodium chloride of analytical. reagent grade rarely showed the effect. Hence it was thought that the change was facilitated by a favourable crystalline habit of the sodium chloride. This favourable habit was obtained by adding formalin and calcium chloride to the aqueous solution of sodium chloride and drying this solution under given conditions. Formalin was added to the sodium chloride solution because it had been observed 